\title{
A new high temperature resistant glass-ceramic coating for gas turbine engine components
}

\author{
SOMESWAR DATTA* and SUMANA DAS \\ Glass-Ceramic Coating Division, Central Glass and Ceramic Research Institute, Kolkata 700 032, India
}

MS received 17 August 2004; revised 29 September 2005

\begin{abstract}
A new high temperature and abrasion resistant glass-ceramic coating system (based on $\mathrm{MgO}$ $\mathrm{Al}_{2} \mathrm{O}_{3}-\mathrm{TiO}_{2}$ and $\mathrm{ZnO}-\mathrm{Al}_{2} \mathrm{O}_{3}-\mathrm{SiO}_{2}$ based glass systems) for gas turbine engine components has been developed. Thermal shock resistance, adherence at $90^{\circ}$-bend test and static oxidation resistance at the required working temperature $\left(1000^{\circ} \mathrm{C}\right)$ for continuous service and abrasion resistance are evaluated using suitable standard methods. The coating materials and the resultant coatings are characterized using differential thermal analysis, differential thermogravimetric analysis, X-ray diffraction analysis, optical microscopy and scanning electron microscopy. The properties evaluated clearly showed the suitability of these coatings for protection of different hot zone components in different types of engines. XRD analysis of the coating materials and the resultant coatings showed presence of a number of microcrystalline phases. SEM micrographs indicate strong chemical bonding at the metal-ceramic interface. Optical micrographs showed smooth glossy impervious defect free surface finish.
\end{abstract}

Keywords. Coatings; glass-ceramic; hot corrosion; abrasion; vitreous enameling; high temperature resistance.

\section{Introduction}

The development of jet aero-engines and rapid advancements in aeronautical, aerospace, automobile and advanced power generation industries created demands for high temperature structural materials (Huminik 1963). The service temperature of existing materials was limited by oxidation, chemical phenomena, erosion and melting. In modern aero-engines, base alloys (substrate) have been designed primarily for light weight and high temperature strength and these advanced materials may not provide optimal corrosion or oxidation resistance. In such cases, the only option is to rely on effective surface coatings to prevent or minimize sulphidation and corrosion problems (Meetham 1986, 1989). Ceramic coatings have found use, not as a substitute for metals and alloys, but to complement metal characteristics by adding further refractoriness, thermal insulation, erosion resistance, oxidation and corrosion resistance characteristics.

In modern gas turbine engines, critical material failures and deterioration problems result from chemical attack, thermal shock, erosion and differences in thermal expansion coefficients. There are five basic reasons, as given here, for using coatings at high temperature (Huminik 1963): (i) For oxidation or corrosion or diffusion control (chemical), (ii) for erosion or abrasion resistance (mechanical), (iii) for electrical applications as a conductor or insulator

*Author for correspondence (sdatta@ cgcri.res.in) (electrical), (iv) for emittance control (radiation) and (v) for conductive heat transfer control (thermal).

Most coatings serve more than one of the above functions, and overall performance is always a compromise. For high temperature oxidation resistance, a coating should (a) resist oxygen and metal ion diffusion, (b) have a low vapour pressure at the operating temperature, (c) have a melting point above the operating temperature, (d) have low reactivity with the substrate, and (e) have low reactivity with the high temperature environment.

There are two basic coating systems: ceramic coatings (Donald 1993) and diffusion coatings (Chatterji et al 1976), which are currently being used in gas turbines to provide improved corrosion resistance and thereby extend component life (Biswas et al 1986; Datta 1995, 1998, 1999a,b, 2003; Datta et al 1998).

In the present paper, the method of preparation and processing of two novel glass-ceramic coating materials, their process of application, characterization and evaluation of coatings are described in brief.

\section{Experimental}

High temperature resistant glass based ceramic coatings preparation by vitreous enameling technique (Andrews 1961; Vargin 1966; Maskal and White 1986) involve several sequential stages. These are: (i) preparation of the coating materials, (ii) processing of the coating materials, (iii) preparation of the substrate surface to be coated, (iv) application of the coating materials, (v) firing and heat 
treatment of the coatings, (vi) inspection of the coatings and (vii) characterization and evaluation of the coatings.

\subsection{Preparation of coating materials}

The coating material compositions (composition ranges in wt\% shown in table 1) are based on inorganic oxides and prepared by the conventional frit manufacturing process by melting a suitably prepared homogeneous batch of various raw materials and subsequently quenching the molten homogeneous glass melt in air on a water cooled stainless steel tray to yield frit (a friable glassy material).

Table 1. Approximate oxide compositions of coating materials studied.

\begin{tabular}{lcc}
\hline Oxide & ABK-13 & ARDB-3 \\
\hline $\mathrm{SiO}_{2}$ & $30-40$ & $40-50$ \\
$\mathrm{MgO}$ & $10-20$ & $1-3$ \\
$\mathrm{ZnO}$ & - & $30-40$ \\
$\mathrm{Al}_{2} \mathrm{O}_{3}$ & $15-25$ & $10-20$ \\
$\mathrm{TiO}_{2}$ & $10-20$ & - \\
$\mathrm{B}_{2} \mathrm{O}_{3}$ & $5-15$ & $1-3$ \\
$\mathrm{CoO}$ & - & $0-1$ \\
$\mathrm{NiO}$ & - & $0-1$ \\
$\mathrm{R}_{2} \mathrm{O}(\mathrm{R}=\mathrm{Na}, \mathrm{K})$ & $5-10$ & - \\
\hline
\end{tabular}

\subsection{Coating material characterization}

The fusion temperature of the coating material is determined by heating a small lump or a small amount of powdered frit in an electrically heated muffle furnace in an oxidizing atmosphere. The coefficient of thermal expansion of the coating material is measured in a Shimadzu Thermal Analyzer DT-30 model dilatometer.

The powdered coating material was analysed by differential thermal analysis technique (Netzsche STA 409C model instrument) to determine the crystallization temperatures for subsequent crystallization. The typical DTA and TGA curves are shown in figure 1.

The coating materials were heat treated at different heat treatment schedules as identified from the DTA analysis to identify various glass ceramics by XRD analysis. The typical XRD pattern of heat-treated ARDB-3 coating material is shown in figure 2. Properties of the coating materials are shown in table 2.

\subsection{Coating material processing (slip making)}

The frit is further processed to make a thick paint like slurry to enable its uniform and thin application on the clean metal parts by conventional spraying or dipping processes. In order to make sprayable slurry, the frit is

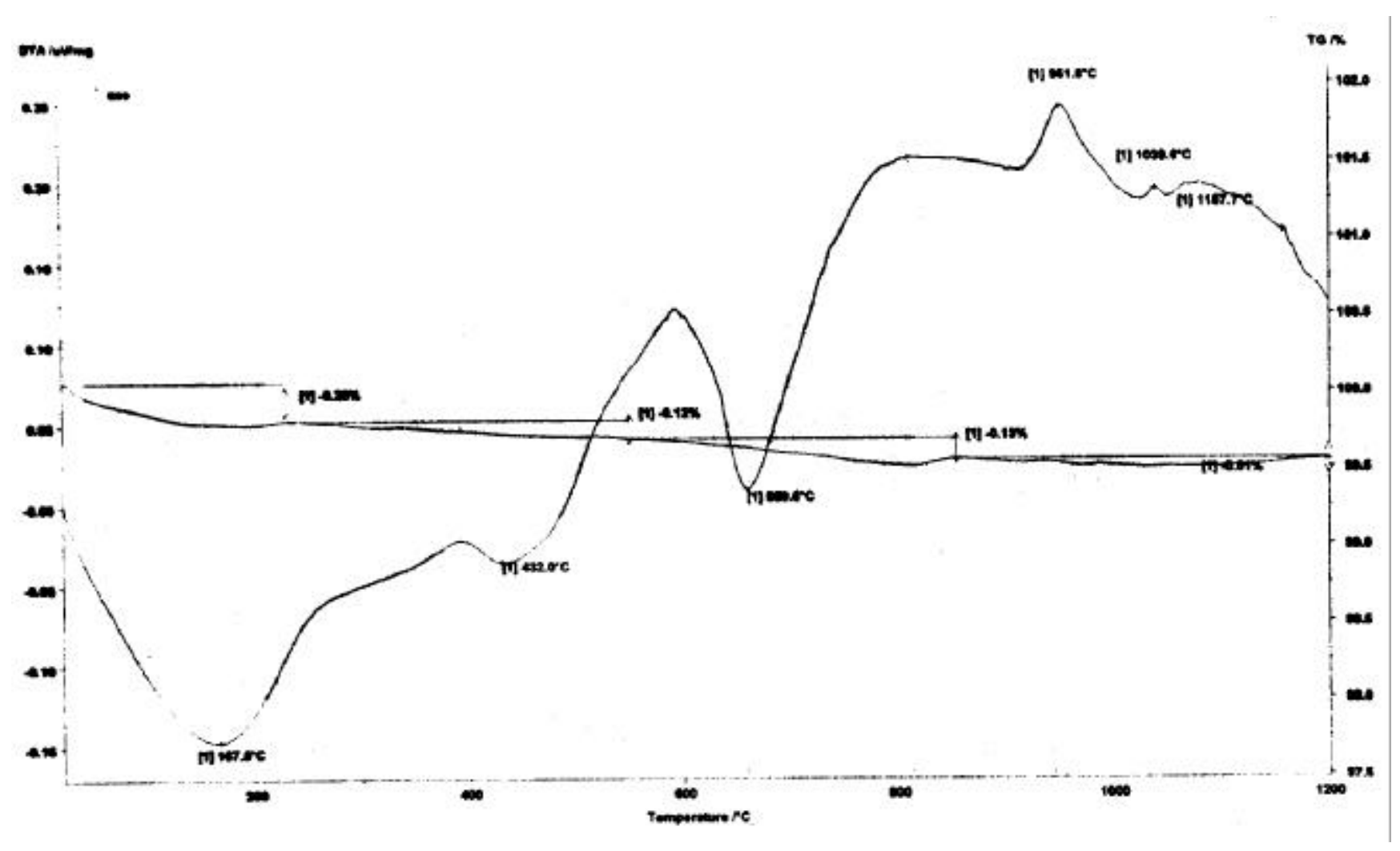

Figure 1. DTA pattern of coating material based on $\mathrm{ZnO}-\mathrm{Al}_{2} \mathrm{O}_{3}-\mathrm{SiO}_{2}$ glass. 
milled in a porcelain ball mill along with various mill additions and water (shown separately in table 3). The rheological properties of the coating material slips are very important for ensuring proper application of the coating on the substrate. The slip is characterized by measuring its specific gravity, particle size distribution and viscosity. The specific gravity of the aged slip is measured using an electronic weighing balance (Shimadzu LIBROR AE-210). The normal specific gravity of a standard slip suitable for spraying a thin coating $(100-150 \mu)$ is in the range of 1.4-1.6. The particle size distribution of the slip is measured by Sedigraph technique. The average particle size of the milled coating materials in the slip form is in the range of $4.4-4.6 \mu$. The viscosity is measured at ambient condition with a Fann cup and bob type viscometer. The results of viscosity measurement at different stress levels are shown in table 4.

\subsection{Metal surface preparation}

Before application of the coating material slip on the metal substrate (thermal expansion, $138 \times 10^{-7} /{ }^{\circ} \mathrm{C}$ from RT to $600^{\circ} \mathrm{C}$ ), the metal surface needs to be cleaned thoroughly by thermal degreasing and sand blasting to remove all contaminants to ensure proper bonding of the coating material with the metal surface.

\subsection{Coating application}

The coating material in the slip form is applied on the clean metal surface by spraying up to the required thickness $(50-70 \mu)$ and dried initially in ambient condition and subsequently in an air oven to remove moisture. The dried coated sample is then fired in a preheated electrical muffle furnace at $1150-1200^{\circ} \mathrm{C}$ for a few min, the coating material then fuses and reacts with the clean metal surface to form a strongly adherent coating. The coating is visually examined and the same operation is repeated to build up required thickness of 100-120 $\mu$ on the metal surface. The coating is again examined visually for any processing defects.

\subsection{Coating characterization}

The thickness of the resultant coating was measured by an eddy current based thickness-measuring instrument (Pulsecho systems) with ND-2 type probe, suitable for non-ferrous alloys. The resultant coating surface has been characterized by optical microscope (Leitz Ortholux polBK optical microscope). The typical optical micrographs of ARDB-3 coating without heat treatment (magnification, 500×) and heat-treated ABK-13 coating (magnifica-

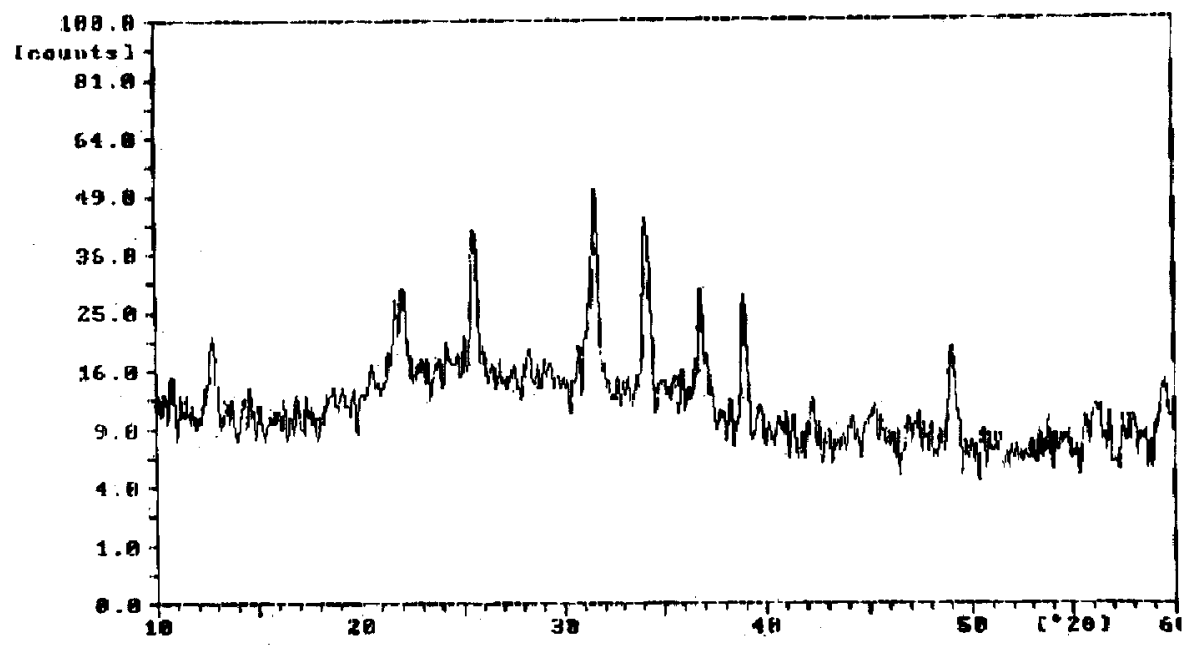

Figure 2. XRD pattern of a typical heat treated ARDB-3 coating material.

Table 2. Properties of coating materials studied.

\begin{tabular}{|c|c|c|}
\hline Property & $\mathrm{ABK} 13$ & ARDB-3 \\
\hline Fusion temperature & $1160^{\circ} \mathrm{C}$ & $1200^{\circ} \mathrm{C}$ \\
\hline Heat treatment schedule & $880^{\circ} \mathrm{C} / 1 \mathrm{~h} \& 1020^{\circ} \mathrm{C} / 1 \mathrm{~h}$ & $980-1000^{\circ} \mathrm{C} / 1 \mathrm{~h}$ \\
\hline Thermal expansion RT to $600^{\circ} \mathrm{C}\left(\times 10^{-7}\right)$ & $72-76 /{ }^{\circ} \mathrm{C}$ & $44-46 /{ }^{\circ} \mathrm{C}$ \\
\hline Phase obtained from XRD analysis & $\begin{array}{l}\text { Magnesium aluminium titanate, } \\
\text { aluminium titanate and magnesium silicate }\end{array}$ & $\begin{array}{l}\text { Willemite, cristobalite and } \\
\text { gahnite }\end{array}$ \\
\hline
\end{tabular}


tion 200x) are shown in figures 3 and 4, respectively. Phase analysis of the resultant coatings before or after heat treatment was done by X-ray diffraction analysis (Philips PW1710 X-ray diffractometer). Depending on the availability of the target material, $\mathrm{CuK}_{\alpha}$ (Ni-filter) was used. Goniometer speed was selected at $\sim 6 \%$ min for different samples. Figure 5 shows a typical XRD pattern of heat-treated ABK-13 coating sample. Figure 6 shows a typical XRD pattern of heat-treated ARDB-3 coated sample. The coating surface was characterized by scanning electron microscope (SE 440 Leo-Cambridge). The samples for SEM study were prepared by suitably etching the surface with very dilute HF solution to reveal the exact microstructure. Some typical scanning electron micrographs of different coating systems studied are shown in figures 7-8. To characterize the coating metal interface, small chips of coated samples was cut perpendicular to the coating plane using a slow speed cutting machine (Isomet, 11-1180, Bucher Ltd., USA) with the help of diamond blades. Figure 9 shows a typical SEM micrograph of the coating metal interface.

\subsection{Coating properties evaluation}

The abrasion resistance property of the coatings was measured as per IS: 3972-1968 standard in P.E.I. Abrasion tester equipment and the results are expressed in terms of loss in weight of the coating material against 50,000 cycles of abrasion. The bond strength of the resultant coating with the substrate was measured indirectly by measuring adherence at $90^{\circ}$-bend test. A $4^{\prime \prime}$ long, $2^{\prime \prime}$ wide and $2 \mathrm{~mm}$ thick coated specimen was forced to bend in the middle to make an angle of $\sim 90^{\circ}$, the amount of coating material chipped off from the bend edge qualitatively indicate the bond strength of the coating.

Table 3. Details of mill additions in wt $\%$ used with different coating systems.

\begin{tabular}{lll}
\hline Mill additions $(\mathrm{g})$ & CG-ABK-13 & ARDB-3 \\
\hline Frit $(-20$ mesh) powder & $100 \cdot 0$ & $100 \cdot 0$ \\
Fume silica & $0 \cdot 0-3 \cdot 0$ & $0 \cdot 0-3 \cdot 0$ \\
Washed $\mathrm{Cr}_{2} \mathrm{O}_{3}$ & $0 \cdot 0-5 \cdot 0$ & $0 \cdot 0-5 \cdot 0$ \\
Cobalt oxide & $0 \cdot 0-0 \cdot 50$ & $0 \cdot 0-0 \cdot 50$ \\
Washed China clay & $0 \cdot 0-5 \cdot 0$ & $0 \cdot 0-5 \cdot 0$ \\
Water & $50-70$ & $50-70$ \\
Milling time & $40 \mathrm{~h}$ & $48 \mathrm{~h}$ \\
\hline
\end{tabular}

Table 4. Viscosity measurement data of ARDB-3 slip.

\begin{tabular}{lllll}
\hline rpm & Deflection & Average & $\begin{array}{l}\text { Viscosity } \\
\text { (c. poise) }\end{array}$ \\
\hline 600 & 7 & 7 & 7 & $3 \cdot 5$ \\
300 & $4 \cdot 5$ & 5 & $4 \cdot 75$ & $4 \cdot 75$ \\
200 & 3 & $3 \cdot 5$ & $3 \cdot 25$ & $4 \cdot 875$ \\
100 & 2 & $2 \cdot 5$ & $2 \cdot 25$ & $3 \cdot 75$ \\
\hline
\end{tabular}

To determine the thermal shock resistance property as per IS: 3972-1968, coated metallic coupons are heated to the desired temperature in an electrically heated furnace and allowed to soak for 5-10 min to attain the thermal equilibrium, then taken out and instantly quenched in cold water at room temperature. Then the sample is examined for any surface damage. The process is repeated till any damage occurs or it passes 10 such cycles. The high temperature resistance of the coating was measured by thermal endurance test at a specific temperature. For thermal endurance test, weighed samples were heated in an oxidizing atmosphere to the desired temperature and allowed to soak for a certain period of time $(25-100 \mathrm{~h})$. After that it is taken out, cooled to room temperature and weighed to measure any weight change to indicate oxidation of metal. Oxidation rates were obtained from gravimetric measurements at selected time intervals. Weight change data were normalized to the total surface area to obtain weight change per unit area. For the cycled samples, the time out of the furnace, which included both cooling and weighing, was $\sim 15 \mathrm{~min}$. The balance used for gravimetric analysis was estimated to have an uncertainty of $\pm 0 \cdot 1 \mathrm{mg}$.

\section{Results and discussion}

\subsection{Magnesium-aluminium-titanate based glass-ceramic system}

The coating material (ABK-13) developed is a magnesiumaluminium-titanate based glass-ceramic composition (as observed in figure 7) which can be applied on nickel base super alloys by vitreous enameling technique. The coating material has a blue colour with white tinges. The firing temperature of the coating material slip is $\sim 1160^{\circ} \mathrm{C}$ which is below the scaling temperature of the substrate

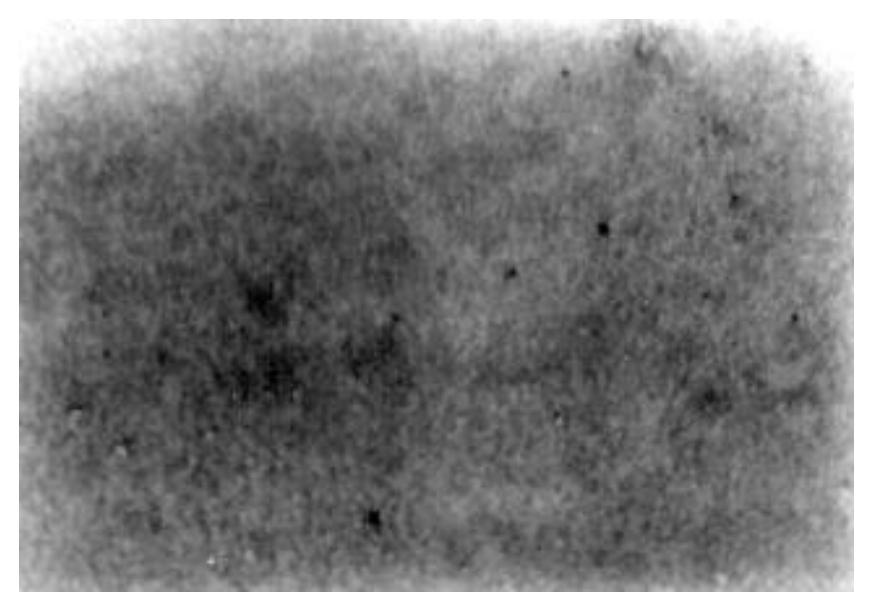

Figure 3. Optical micrograph of ARDB-3 virgin coating at $500 \times$ magnification 
metal. After proper firing the resultant coating shows a glossy bluish steel gray colour without any visible defects, which after proper heat treatment becomes a glassceramic with dirty gray colour and less glossy (figure 5). The thermal expansion coefficient of the coating material from room temperature to $600^{\circ} \mathrm{C}$ is $\sim 70 \times 10^{-7}$ which is quite low in comparison with that of nickel based super alloys $\left(138 \times 10^{-7}\right)$. However, this gives a very good adherent coating when thin coating $(100-150 \mu)$ is applied. The processing parameters (milling time, milling charge, mill additions etc) for the preparation of coating material slip are standardized to obtain the optimum properties (particle size and specific gravity) to get the required thin coating without any defect. Because of this large difference in the linear thermal expansion coefficient between coating material and metal substrate, the coating has been

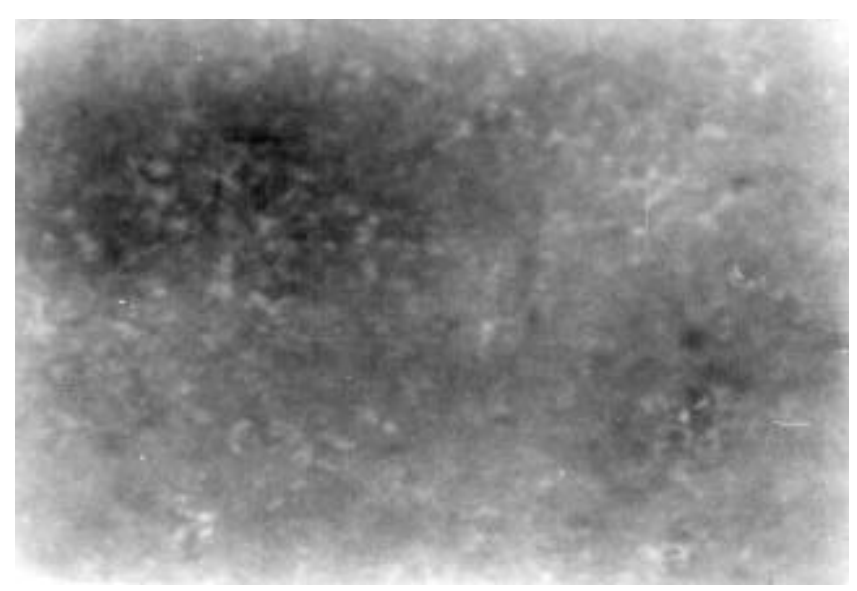

Figure 4. Optical micrograph of heat-treated ABK-13 coating at $200 \times$ magnification. applied in two stages of application to avoid generation of excessive stress within the glass (coating)-metal interface and achieve the desired thickness and finish.

The DTA pattern of the coating material showed two transitions, one endothermic at $880^{\circ} \mathrm{C}$, the nucleation temperature and the other exothermic at $1020^{\circ} \mathrm{C}$, the growth temperature. The heat-treatment of the resultant glassy coating yielded one glass-ceramic coating. The XRD analysis of the resultant glass-ceramic coating indicates magnesium aluminium titanate as the major phase along with magnesium silicate and aluminium titanate as minor phases. The scanning electron micrograph of heat treated coating (Biswas et al 1986) indicates a homogeneous microstructure with predominant dispersion of tiny (1$2 \mu)$ magnesium-aluminium-titanate micro-crystals. This unique microstructure is responsible for the excellent abrasion resistance property of the resultant heat treated coatings. The microstructure showed impervious nature of the coating which accounts for the oxidation and hot corrosion resistance of the coating, because the coating acts as a physical barrier between the environment and the metal substrate even at high operating temperature.

The Vicker's microhardness of the coating using $100 \mathrm{~g}$ load is $\sim 840 \mathrm{HV}$ and abrasion resistance measured in a PEI abrasion tester is $0.6 \mathrm{mg} / \mathrm{cm}^{2}$ loss in weight after 50,000 cycles. The thermal shock resistance of the glassceramic coating was found to be more than 10 cycles when repeatedly heated to $750^{\circ} \mathrm{C}$ and immediately quenched in cold water and examined for any chipping or spalling defects. The $90^{\circ}$-bend test showed only traces of coating chipping off from the most convex surface which indicates strong adherence of coating with the alloy substrate. The operating temperature of this coating system is limited to $750^{\circ} \mathrm{C}$ and cannot be used successfully at engines having higher operating temperature like $1000^{\circ} \mathrm{C}$.

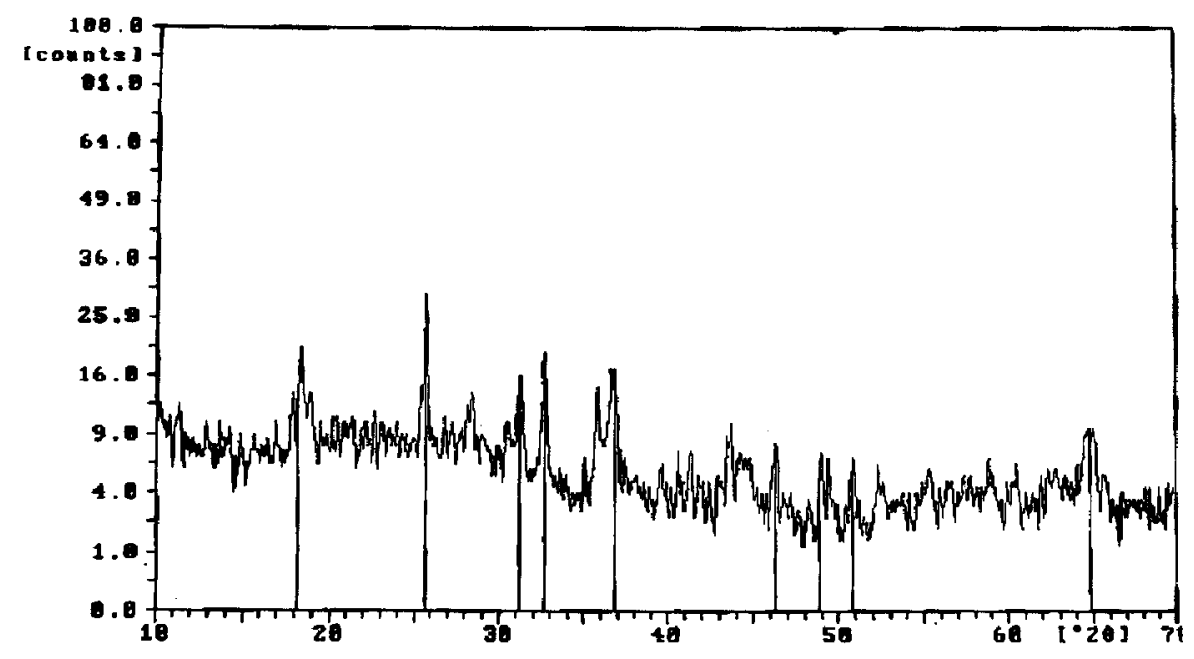

Figure 5. XRD pattern of heat treated ABK-13 coating. 


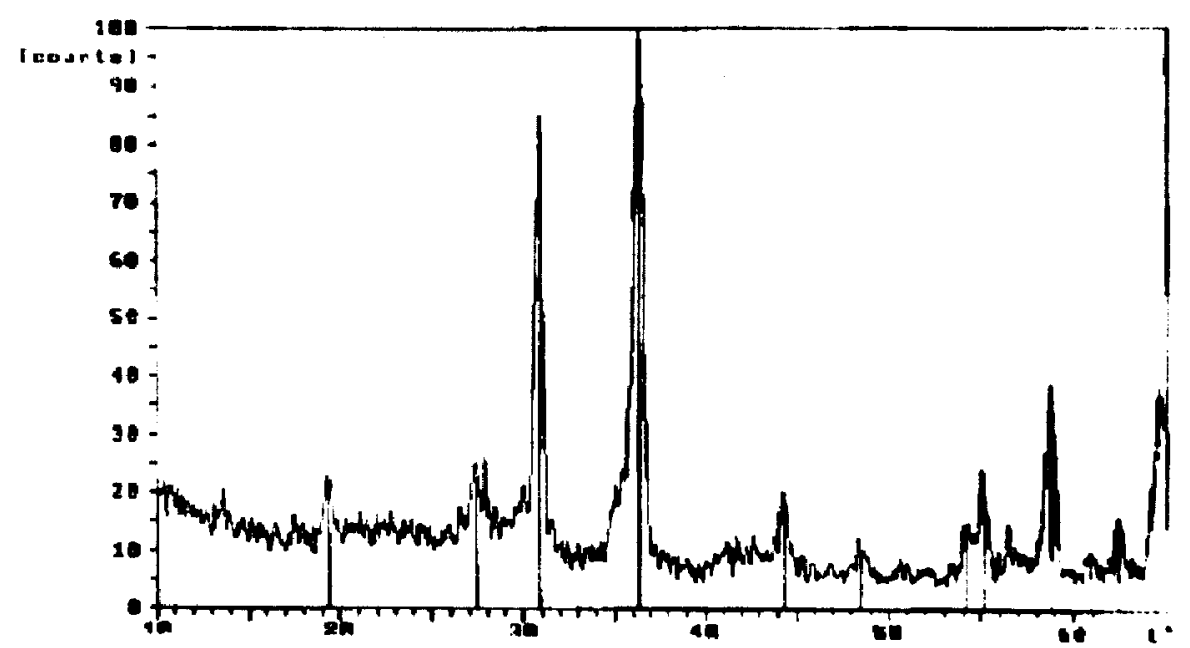

Figure 6. XRD pattern of heat-treated ARDB-3 coating.

\subsection{Study of $\mathrm{ZnO}-\mathrm{Al}_{2} \mathrm{O}_{3}-\mathrm{SiO}_{2}$ based coating system}

In order to achieve a coating system having similar mechanical and thermal properties which can operate at higher working temperature like $1000^{\circ} \mathrm{C}$, some new compositions were formulated based on $\mathrm{ZnO}-\mathrm{Al}_{2} \mathrm{O}_{3}-\mathrm{SiO}_{2}$ system. The reason of selection of this type of glass systems is manifold, as shown below (Donald 1993).

- The glasses in this system can be melted at suitably lower temperatures $\left(\sim 1450^{\circ} \mathrm{C}\right)$.

- The constituent oxides possess a relatively low vapour pressure at desired working temperature of the coating $\left(1000^{\circ} \mathrm{C}\right)$.

- These glasses can be suitably heat treated to generate a variety of glass ceramics having superior set of properties and desired thermal expansion coefficients.

Based on the literature data (Donald 1993), suitable glass compositions are designed for having thermal stability for continuous use at $1000^{\circ} \mathrm{C}$ and also having comparable mechanical and thermal properties. A number of glass compositions (ARDB-3 in table 1) have been melted and studied to generate different glass-ceramics. The typical DTA curve (figure 1) showed number of nucleation and growth temperatures at $\sim 600,660,952,1040$ and $1160^{\circ} \mathrm{C}$, respectively. The typical linear thermal expansion coefficient of the coating material is $44-46 \times$ $10^{-7} /{ }^{\circ} \mathrm{C}$ from RT to $600^{\circ} \mathrm{C}$. Subsequent heat treatment of the amorphous coating materials using different heat treatment schedules resulted in a variety of glass-ceramics, which were characterized by XRD analysis (powder diffraction file 1967).

These coating materials can be processed and applied as a coating on metal substrates at a temperature of $1200^{\circ} \mathrm{C}$. But the resultant coatings are porous and not very glossy because of higher maturing temperature and porosity.

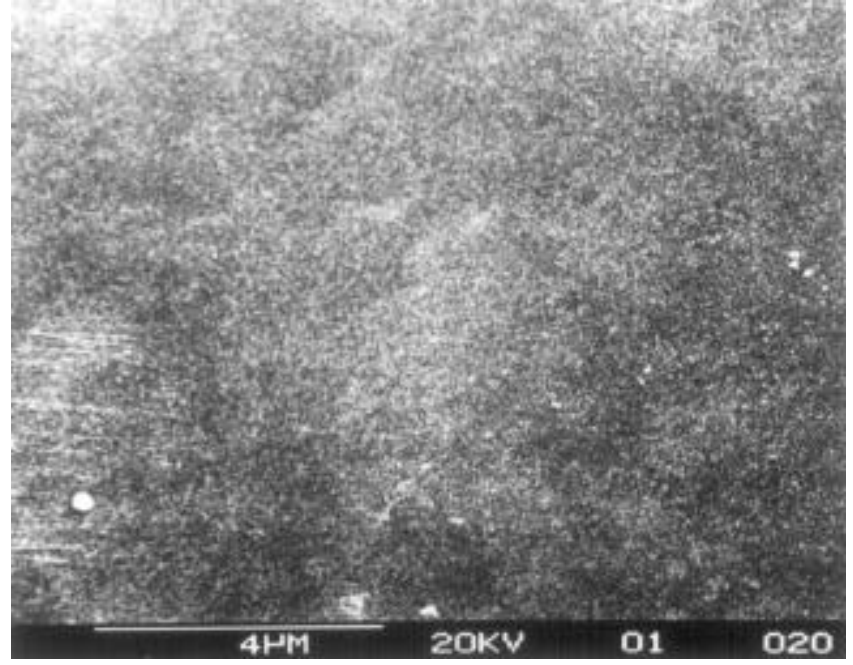

Figure 7. SEM micrograph of virgin CG-ABK-13 coating.

Further heat-treatment or prolonged exposure to working temperature $\left(1000^{\circ} \mathrm{C}\right)$ reduced the abrasion resistance of the resultant coating and increased crystal content which adversely affected thermal expansion coefficient and resulted in premature failure of the coating in thermal shock measurement test.

Further, the coating upon thermal endurance test at $1000^{\circ} \mathrm{C}$ for $25 \mathrm{~h}$ became matt and the colour changed from greenish gray to steel black and increase of weight is observed. This colour change may be due to excessive oxidation of the base alloy caused by excessive permeation of oxygen through the pores present in the coating followed by diffusion of resultant metal oxide in the coating matrix. To increase the amount of glassy phase in the resultant coating (in order to lower down the maturing temperature and reduce porosity in the resultant coatings) as well as to improve workability, the above zinc 
alumino silicate based coating material is blended along with some standard high temperature resistant coating compositions like ABK-103 (a $\mathrm{BaO}-\mathrm{MgO}-\mathrm{SiO}_{2}$ glass), $\mathrm{B}-55 \mathrm{~A}$ (a $\mathrm{BaO}-\mathrm{SiO}_{2}$ glass) and $\mathrm{ABK}-13$, respectively. The resultant coatings in all the three cases after firing at $1200^{\circ} \mathrm{C}$ were found to possess glossy appearance, characteristics of a vitreous coating. At the first instance, the abrasion resistance property of these coatings was measured. The results indicate that in case of mixed coat with ABK-13 the resultant coating (ARDB-3) exhibits a loss in weight value of $\sim 0.4-0.5 \mathrm{mg} / \mathrm{cm}^{2}$. In the other two cases, the abrasion resistance of the resultant coatings was found to deteriorate as compared with the starting coatings and these compositions were not persuaded any further. The resultant coating ARDB-3 has good glossy surface finish without any porosity and the processing is simple. The thermal shock resistance test carried out at $1000^{\circ} \mathrm{C}$ for 10 cycles also indicates its suitability. By studying the abrasion resistance property of resultant coatings over a wide compositional variation, the optimized composition of this mixed coating system was found to belong to a $50: 50 \mathrm{wt} / \mathrm{wt}$ ratio.

\subsection{Study of thermal endurance and thermal shock resistance of resultant mixed coating (ARDB-3)}

The thermal properties of the resultant coatings (ARDB3 ) are as targeted. Thermal shock resistance is $1000^{\circ} \mathrm{C} / 10$ cycles and thermal endurance test at $1000^{\circ} \mathrm{C} / 100 \mathrm{~h}$ showed no chipping and negligible weight gain as shown in figure 10. One nickel based super alloy substrate of similar dimension and weight was used as a control during the thermal endurance test. The changes in weight of the samples were plotted with time and the result shows that the coating provides oxidation resistance to the underlying substrate metal. Moreover change in working temperature by $50^{\circ} \mathrm{C}$ does not effectively change the oxi-

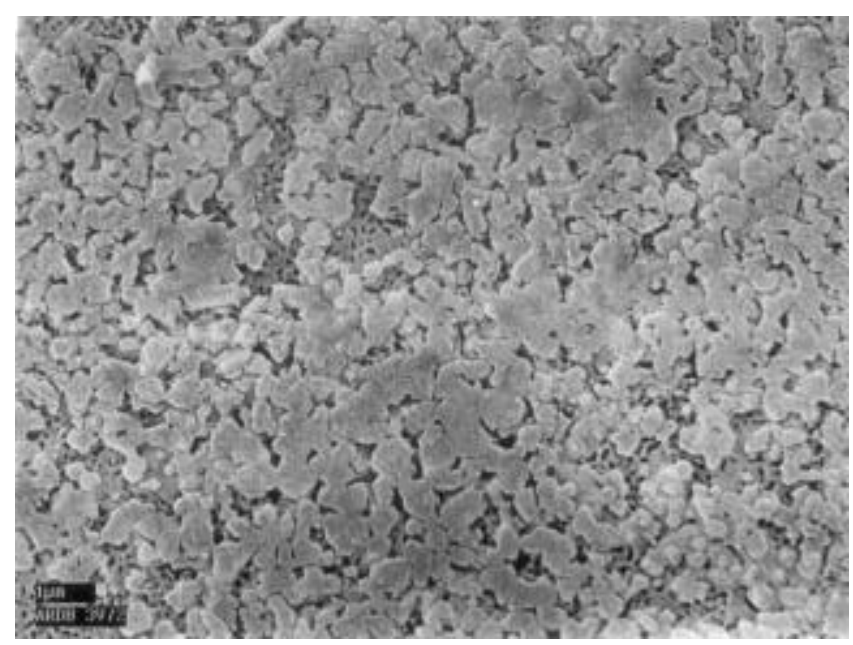

Figure 8. SEM micrograph of heat treated ARDB-3 coating. dation resistance of the coating. Only complete crystallization along with change of colour of the coating is observed.

\subsection{Characterization of coating}

The XRD analysis reveals presence of only gahnite as the major crystal phase in the coating (shown in figure 6) although, in the heat treated coating material, willemite and cristobalite phases are also present as major phases. This new glass-ceramic is absolutely unique in nature, because zinc alumino silicate, magnesium aluminium titanate and magnesium zinc silicate glass ceramics are all well studied in the literature but report of any glassceramic with gahnite as major phase has not been reported earlier (Donald 1993). This apparently unusual change in the resultant microstructure could possibly be due to the presence of significant amount of magnesiumaluminium-titanate-based glass in conjunction with highly crystallizable zinc alumino silicate glass ceramic in the coating matrix. In fact, presence of the second glassy matrix possibly helped to increase the amorphous nature

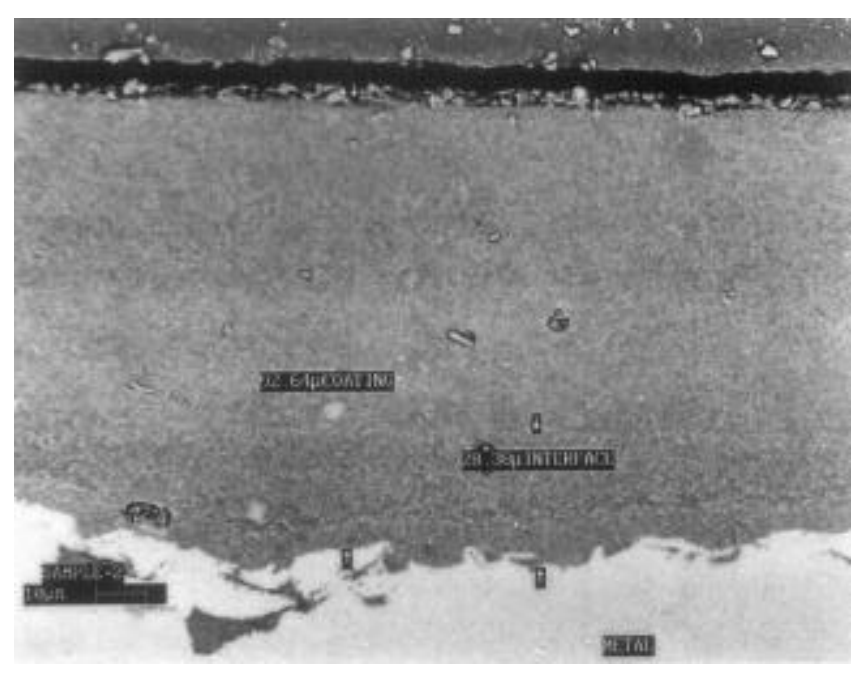

Figure 9. SEM micrograph of ARDB-3 coating interface.

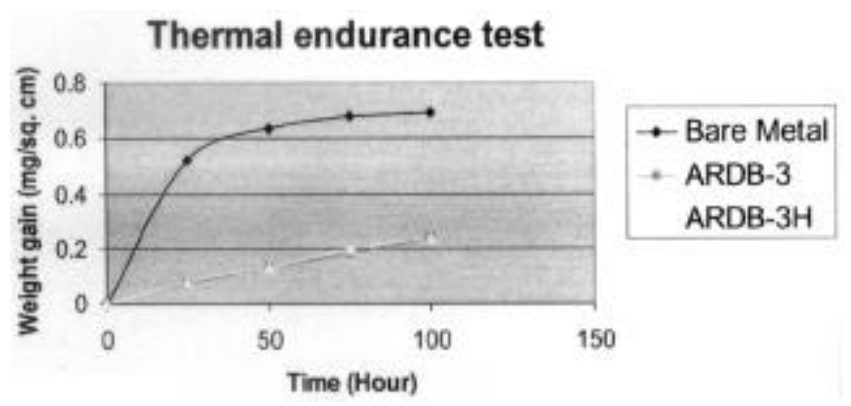

Figure 10. Results of thermal endurance test at $1000^{\circ} \mathrm{C}$ for $100 \mathrm{~h}$ (ARDB-3H indicates similar test at $1050^{\circ} \mathrm{C}$ for same time). 
of the resultant coating (as evident from the glossy nature of the coating) and induces magnesium aluminium titanate crystallites during firing of the coating. These crystallites or nucleuses prompt the selective formation of gahnite crystal phases having similar crystal structure (at the expense of willemite and cristobalite crystal phases) in the resultant coating during subsequent heat treatment. The coated samples were examined by optical microscopy and SEM (figures 3 and 8). These micrographs showed homogeneous impervious microstructures which also corroborates with the above explanation and experimentally observed data (Sen et al 1989; Majumdar and Jana 2001). Figure 9 shows the SEM micrograph of the coating metal interface, which showed a continuous graded interface with highly corroded metal surface indicating strong chemical bonding and excellent adherence of coating with the metal substrate.

\section{Conclusions}

(I) Two new glass compositions (based on magnesiumaluminium-titanate and $\mathrm{ZnO}-\mathrm{Al}_{2} \mathrm{O}_{3}-\mathrm{SiO}_{2}$ glass systems) suitable for application on nickel base super alloys has been developed.

(II) The process of application of the developed coating materials to yield high temperature resistant coatings on nickel base super alloys for gas turbine application has been standardized.

(III) The $\mathrm{ZnO}-\mathrm{Al}_{2} \mathrm{O}_{3}-\mathrm{SiO}_{2}$ based coating (ARDB-3) is suitable for continuous use at $1000^{\circ} \mathrm{C}$ temperature.

(IV) The developed coatings exhibit high abrasion resistance (loss in weight value of $0.4-0.6 \mathrm{mg} / \mathrm{cm}^{2}$ in 50,000 cycles in P.E.I. abrasion tester).

(V) The coatings exhibit high thermal shock resistance (no chipping or spalling) on 10 cycles of thermal shock between room temperature and the working temperature.

(VI) The $\mathrm{ZnO}-\mathrm{Al}_{2} \mathrm{O}_{3}-\mathrm{SiO}_{2}$ based coating (ARDB-3) exhibits negligible increase in weight after $100 \mathrm{~h}$ of static oxidation test at $1000-1050{ }^{\circ} \mathrm{C}$.

\section{Acknowledgements}

The authors wish to thank Dr (Mrs) S Sen for SEM, Dr
A Chakravorty for XRD analysis and $\mathrm{Dr} \mathrm{D}$ Basu for DTA.

\section{References}

Andrews A I 1961 Porcelain enamels (Illinois, USA: The Garard Press)

Biswas K K, Datta S, Das S K, Ghose M C, Mazumdar A and Roy N 1986 Trans. Ind. Ceram. Soc. 4543

Chatterji D, DeVries R C and Romeo G 1976 Protection of superalloys for turbine application, in Advances in corrosion science and technology (eds) M G Fontana and R W Staehle (New York: Plenum Press) Vol. 6, pp 1-87

Datta Someswar 1995 Handbook of ceramics (ed.) S Kumar (Calcutta: Kumar \& Associates) Vol. II, pp 289-299

Datta S 1998 Bull. Mater. Sci. 21421

Datta S 1999a High temperature resistant coatings for aeronautical application, in National seminar on coating, plating and paints-99 (Koraput: H.A.L.)

Datta S 1999b High temperature resistance coatings for gas turbine components for aeronautical applications, in National seminar on engineering ceramics: Prospects in the new millennium (Kolkata: CGCRI)

Datta S 2003 A synergistic composition useful for making thermally stable non-metallic coating on metals, Patent application no. 98/DEL/03

Datta S, Guha A K, Sarkar S and Majumdar A 1998 Silicoaluminising and heat treatment protective coatings developed at CGCRI, Kolkata, in National seminar on indigenization and vendor development (Koraput: H.A.L.)

Donald I W 1993 J. Mater. Sci. 282841

Huminik J Jr 1963 High temperature inorganic coatings (New York: Reinhold Publishing Corporation) pp 68-69

Majumdar A and Jana S 2001 Bull. Mater. Sci. 2469

Maskal K A and White D 1986 Vitreous enamelling: A guide to modern enamelling practice (London: Institute of Ceramics, Pergamon Press)

Meetham G W 1986 Mater. Sci. Technol. 2290

Meetham G W 1989 Recent advances and developments in coatings, in Seminar on advances in plating and coating technology, Bangalore

Powder diffraction file (Revised) 1967 Pub. Joint Committee on Powder Diffraction Standards

Sen R, Datta S, Das S K and Basu S K 1989 Wear 130249

Vargin V V 1966 Technology of enamels (London: Maclaren and Sons Ltd) 